\title{
Legal Issues Arising from Smart Contracts under the Iraqi Law
}

\author{
Ahmed Aziz Hassan \\ College of Law, University of Sulaimani, Kurdistan Region - F.R. Iraq \\ Faculty of Law and Politics,University of Human Development, Kurdistan Region - F.R Iraq
}

\begin{abstract}
Smart contracts can be defined as computer codes which are run digitally by computer programs to utilise the negotiation, formation, and performance of an automated and irreversible agreement between the contracting parties. Smart contracts are distinguished from other forms of contracts in terms of the way they are concluded which is through Blockchain Technology. In contrast to conventional contracts established through speech, written words or actions, smart contracts are algorithmic and self-executing agreements. In this article, smart contracts will be discussed from the perspective of their general rules and features and the Iraqi law. This study analyses the formation mechanisms of the general principles in Iraqi law governing the contracts and how these mechanisms can be applied to the new technological framework of smart contracts. In addition, integrating smart contracts into the current legal provisions in Iraq is examined.
\end{abstract}

\section{Introduction}

Many contracts are concluded and performed every moment in different aspects of our life. Nowadays, several contracts and transactions are formed and implemented online. Therefore, many legislators have introduced new laws or rules to regulate such new forms of electronic transactions. For example, according to Article 12 of the UN Convention on the Use of Electronic Communications, an agreement is considered valid and legally enforceable when it is concluded through automated messages [1]. In 2012, the Iraqi legislator enacted a new law to regulate electronic signature and electronic transactions [2]. Some of these contracts are concluded in a mixed form, i.e. in paper form as well as electronical form. There is also an evolution in the form of contracts as they are signed only electronically and through running a computer code which can replace the traditional paper contracts. These contracts are known as smart contracts. The term 'smart contracts' was first used nearly 25 years ago, by a digital currency researcher, Nick Szabo [3] [4]. The recent technological advancements, such as Bitcoin and Blockchain, have increased interest and excitement for doing more research in the field [5]. Smart contracts (also known as Self-executing Contracts, Blockchain Contracts or Digital Contracts) are, in general, computer programs which work as agreements and include terms and conditions with the ability of self-execution and self-enforcement. They enable the parties to conclude their commerce, usually through the internet, without any mediator. They are also defined as enforceable agreements which are executed automatically by a computer, although human input and control may be required in some parts of the agreement [6]. These contracts can be divided into two main types: cryptocurrencies, which follow simple instructions to transfer coin units from an account to another, and complete smart contracts which are run through Ethereum blockchain [7, p. 333]. The term of Blockchain was first introduced by Satoshi Nakamoto, in 2008, when he invented Bitcoin, which was the first digital currency [8, p. 1]. This technology is a decentralized network which is not owned by governments and it plays the role of monitoring and registering all the transactions regarding the digital asset. Smart Contracts can be seen in several forms such as; code format, traditional contracts in a codified form or a combined version of both computer codes and traditional contracts $[5$, p. 6]. This research discusses the main features of smart contracts and evaluates some major problematic aspects of smart contracts in accordance with the Iraqi law provisions regulating these contracts.

\section{Key Features of Smart Contracts}

\subsection{Electronic Nature:}

This is one of the main differences between traditional contracts and smart contracts. Traditional contracts are concluded, generally, either in oral or written forms. The development of e-commerce led to increasing the existence of electronic contracts such as click-wrap agreements and browse-wrap agreements [9].

A click-wrap agreement is usually seen as part of the installation process of a software program in which the user has no bargaining power i.e. the customer has no other options but to take it or leave it. If the user wants to use the product or the service, he shall accept terms, as they are, by clicking on "I agree" or "I accept" or "OK" then the agreement is formed. Otherwise, he cannot use or buy the product if he rejects any term. A browse-wrap agreement is an agreement between the provider and the user to make the content of a website or a downloadable product available to the user. The user gets access to the materials or continues using the product only if he accepts the terms and conditions of the web page. Generally, it is assumed that the user's continued use of the website or the downloaded software indicates user's acceptance to the terms [9] [10, p. 186].

Journal of University of Human Development

Volume 4 No. 4(2018); DOI: 10.21928/juhd.v4n4y2018.pp42-47

Regular research paper :(6) Received 2 July 2018; Accepted 27 July 2018; Published 06 October 2018

Corresponding author's e-mail: ahmed.hassan@univsul.edu.iq

Copyright (C 2018 Ahmed Aziz Hassan . This is an open access article distributed under the Creative Commons Attribution License (CC BY-

NC-ND 4.0) 
However, e-commerce contracts may not be solely concluded electronically and there may be still some paper documents needed such as invoice and delivery certificate when they are covering the purchase of offline goods or services. In this case, the paperwork is the only evidence for the existence of an electronic contract [11, p. 124]. In smart contracts, it is not possible to have any other form, such as oral or written, except electronic form to conclude, execute and enforce such contracts $[11$, p. 124].

Additionally, smart contracts can be distinguished from other electronic contracts in terms of the specifics of the subject matter. It is argued that what distinguishes smart contracts, from other forms of contracts, is the form of the object of the contract. In smart contracts, the object shall be a smart object. This means, the usage and the disposal of the property must be able to be controlled by digital means [12, p. 137]. Smart contracts have a specific subject matter such as digital assets (cryptocurrency) or digital representation of offline assets [5, p. 7]. In contrast, electronic contracts, such as click-wrap agreements, which are also concluded electronically, do not create positive commitments on the user [11, p. 124].

\subsection{Increased Certainty:}

Smart contracts are expressed and concluded through computer programs and their terms and conditions are stated in computer languages. These terms and conditions are interpreted by computers based on Boolean logic, in which there is no chance for discretion; the statement is either true or false and there is nothing in between [11, p. 125]. In traditional contracts, the terms of the contract are interpreted by human brain based on certain criteria and the way of thinking. Thus, the interpretation of smart contracts by programming languages is more precise and leads to mitigate potential issues related to unpredictable interpretation of the terms by the contractual parties or the enforcement agencies [11, p. 125]. In addition, the ambiguity in programming languages is less than that in traditional contracts, because computers can recognize fewer terms compared to the human brain [5, pp. 7-8]. Moreover, Smart contracts are stand-alone contracts. The computer code, which represents the smart contract, is the sole arbitrator of the deal without the need for jurisdiction or interpretation by any entity [11, pp. 125-126]. Therefore, smart contracts can minimize the need for contract interpretation in addition to the significant reduction of the contract drafting and execution costs [13, p. 13].

\subsection{Conditional Nature:}

As stated above, smart contracts are concluded through computer codes. These codes are based on conditional statements such as conditioning a certain result on a specific event, for example if $\mathrm{X}$ then Y. In codifying a smart contract, conditional statements are crucial and the code can only perform what it is programmed to do [5, p. 7]. These conditional statements are in harmony with the terms and conditions of the contract, and consequently, the enforcement of smart contracts is the result of running circumstances through a conditional statement [11, p. 126].

\subsection{Self-enforceability and Self-sufficiency:}

In traditional contracts, performance is not secured since it depends on the willingness of the parties. Smart contracts, in contrast, ensure a greater level of performance which is irrevocable and automated, as the unchangeable computer code ensures its performance and enforcement without any alteration by the parties [7, p. 333]. After concluding a smart contract, it does not depend on the will of the contractual parties anymore and it will be enforceable automatically without the need for any approvals from the parties. Thus, once a smart contract is concluded, it is binding for all its parties without depending on human mediatory. Even if there is a change in circumstances or the intent of the parties, it does not affect the enforceability of the contract. The computer code, which represents and runs the contract, authenticates the conditions, transfers assets (the subject matter of the contract), and makes entries in the Blockchain database about such transactions [11, p. 126]. Due to this self-enforceability feature, it is claimed that smart contracts are not only a subset of traditional contract law but they can also substitute a system of legal enforcement [14, p. 12].

Self-sufficiency means Smart contracts do not depend on any legal agencies to exist or to enforce, in contrast to classic contracts, in case of incompleteness [11, p. 127]. Thus, it can be said that smart contracts provide more accurate, more efficient, cheaper and quicker enforcement of contracts [10, p. 183].

\section{Smart Contracts from the Perspective of the Iraqi Law}

In Iraq, contracts are mainly governed by the provisions of Iraqi Civil Code no. 40 of 1951 [15]. The provisions of this law include the general principles which apply to the contracts in general. In addition to the Civil Code, in order to keep pace with the development of electronic transactions and globalisation, Electronic Signature \& Electronic Transactions Law No. 78 of 2012 was enacted to govern electronic signature and electronic transactions [16, p. 58]. The law, however, includes few provisions regarding electronic contracts. Therefore, in this research, the term of "Iraqi law" is used to refer to The Iraqi Civil Code unless otherwise precisely stated.

According to Iraqi law, one of the sources of obligations is contracts. A contract, according to Article 73 of the Iraqi Civil Code, is defined as the unison of an offer made by a contracting party with the acceptance of another party in a manner which establishes the effect thereof in the object of the contract. As it can be read from the definition, the obligations arising from contracts are regulated by the agreement of the parties, i.e. the contracting parties are obliged to comply with the terms and conditions agreed upon in the contract, and the contract is the source of their obligations.

One of the principles of contracts in the law is the doctrine of freedom of contract. According to which, parties have freedom in choosing the terms of their contracts. However, this freedom is not without limits and is regulated by the mandatory provisions in the laws, aiming at protecting weaker parties. Further, such terms cannot contradict the law, morals, customs and public policy and order $[15$, arts. $75,132(1)]$.

In Iraqi law, there are several stages in the lifetime of contracts. It primarily starts with negotiation, where the parties intimate their desire to enter into a contract. This stage is the stage of offers and counteroffers from the parties. Hereafter, if the parties agreed upon the essential elements of their contract, the contract enters the next stage which is the perfection stage, and from this point, 
the contract is considered concluded. Finally, the contract enters into the performance stage where the parties perform their obligations as agreed upon in the contract until the contract is fully implemented. However, if a party does not fulfil its obligations under the contract as agreed upon, this situation is considered as breach of contract.

To conclude a valid contract under the Iraqi law, there must be three elements which are: mutual consent of the contracting parties [15, art. 77], a certain object which is known as the subject matter of the contract [15, art. 126] and the cause of the contract (obligation) [15, art. 132]. If one of these elements does not exist, there is no contract and neither of the contracting parties is obligated to comply the terms and conditions, because these elements are the mandatory requirements to conclude the contract. Generally, if these three elements meet, the contract is considered to be concluded and it binds the parties. However, in addition to these three elements, there are some additional requirements need to be met for some contracts in order to be considered as valid contracts under the provisions of Iraqi law such as writing or registration.

Basically, it can be said that smart contracts can meet the requirements to conclude a valid and enforceable contract. However, the issue is not that simple to apply these requirements, as they are, to smart contracts and several difficulties and challenges may arise in the detail, such as; Jurisdiction, applicable law [16], meeting of the minds (consent), consideration, capacity and reason [17, p. 368]. In this paper, some of the legal issues are analysed bellow.

\subsection{Consent ( Meeting of the Minds): Offer and Acceptance}

Generally, for a contract to be validly concluded, there must an offer expressed by one party (offeror) and acceptance of the offer by the other party (offeree) [18, p. 4]. An offer shows one party's intent to conclude a contract with the other party, to whom the offer is addressed, and when the other party accepts the terms of the offer, the contract is concluded [19, p. 42].

According to Iraqi law, the offer and acceptance can be expressed orally or by correspondence and by a common usage sign as they can also be met by actual exchange representing mutual acceptance, and by any other method provided that there is no doubt of mutual acceptance [15, art. 79]. In electronic contracts and according to the Electronic Signature \& Electronic Transactions Law No. 78 of 2012, both offer and acceptance can be expressed electronically [2, art. 18(1)]. In addition, displaying goods with their prices is considered as an offer [15, art. 80(1)]. However, publishing, advertising and listing common prices addressed to public or individuals is an invitation to negotiate not an offer [15, art. 80(2)]. Therefore, based on these provisions, contracts can be concluded electronically through emails, internet (online ledger) or any other method.

As smart contracts are in the form of computer codes, which represent the agreement between the parties, a complicated issue may arise here is meeting of the minds of the parties [12, p. 141]. In such contracts, the consent of the parties is represented by signing the agreement cryptographically [20, p. 22]. This is because computers do not have minds to express the will and consent of the parties. In smart contracts, submitting the cryptographic keys by the parties to commit their resources can be considered as the proof of the parties' intent to contract.

However, expressing the mutual intent of the parties in this way does not mean their minds met regarding the specific terms of their contract, and this may cause misunderstanding regarding the contract or specific terms. For example, in traditional contracts, according to the doctrine of mutual mistake, the parties of an agreement are excused from performing their obligations when they are mistaken about an essential point in this contract and the court can set the contract aside [21, p. 413]. Generally, the mistaken party shall not be excused from the performance of the contract, unless the other party had committed the same mistake or had knowledge regarding the mistake or could have easily discovered the mistake [15, art. 119]. Therefore, such an agreement is not enforceable because of misunderstanding and mutual mistake. In smart contracts, there is no such unenforceability, the contract would go ahead and execute itself automatically.

Additionally, there might be executable smart contracts before satisfying the requirements of the mutual consent of the parties and they cannot be amended in accordance with the events that may arise especially when the parties do not expect the exact scenarios that may arise during the implementation of the contract. Most of the smart contracts are considered to be incomplete with regard to not specifying possible outcomes that arise in different jurisdictions. In addition, because of their selfexecuting feature, courts cannot fill these gaps in the expression of the parties' intent [17, p. 369].

Another problem, regarding meeting of the minds in the smart contracts, is the distinction between validity of the contract and its enforceability [14, p. 33]. For example, when a party enters into a contract due to duress or fraud, the contract itself is valid but its performance is suspended on the approval of the aggrieved party [15, arts. 115,121$]$. When a party to a contract takes advantage of the other party's need, urges, cravings, harshness or inexperience to conclude a contract, the exploited party is entitled to demand reasonable redress or revoking the contract within one year from the time of concluding the contract [15, art. 125]. In smart contracts, this distinction cannot be done. Once a smart contract is concluded, according to the procedures on blockchain ledger, it is directly enforceable even if it is concluded under duress because the system does not have any idea about why the party provided private keys to conclude a smart contract. Later, the party cannot ask for excusing the performance of the signed contract because the system is run by computers and computers only follow the code of the smart contract itself and nothing more. However, the party can sue for restitution after executing such a contract $[17$, p. 376].

Regarding the time and place of concluding contracts, Iraqi Civil Code states that a contract is deemed concluded at the time and place that the offeror becomes aware of the acceptance [15, art. 87(1)]. Therefore, in contracts concluded by telephone or any other similar methods of communication, the time of concluding the contract is the same as contracting between present parties [15, art. 88]. For the place, it is deemed as contracting between absent parties [15, art. 88], i.e. the place where the offeror becomes aware of the acceptance [15, art. 87(2)]. Therefore, a smart contract is concluded when the contract cryptographically signed by both party, not the moment of registering the contract on blockchain [20, p. 23]. 


\subsection{Consideration (Cause):}

Another basic requirement to conclude an enforceable contract is consideration [5, p. 11]. Every contract must have a lawful cause according to Iraqi law [15, art. 132(1)]. Having a lawful cause for every obligation is presumed even if it is not stated in the contract unless the contrary is proved [15, art. 132(2)]. Therefore, a contract is deemed null and void if it does not have a cause or its cause is unlawful or contrary to the public order or the public moral.

In addition, it is argued that the consideration shall be given at the time of concluding the contract or at some point after the contract is made, but 'past consideration' cannot be used to conclude an enforceable contract [21, p. 118]. This requirement distinguishes unenforceable gifts from binding contracts. In contrast to contracts, promises may not create legally binding obligations. In concluding smart contracts, consideration is not investigated. However, reciprocal promise by the parties of a smart contract is considered as consideration. If someone encodes a donation promise to the blockchain, this promise will irrevocably execute itself in the same way as smart contracts, and then it cannot be stopped. In addition to the existence of consideration, consideration shall be adequate and sufficient. In smart contracts this cannot be seen since there is no test of enforceability before execution of the contract [17, p. 370].

\subsection{Capacity:}

According to Iraqi law, every person has the capacity to enter into a contract unless this capacity is determined as incompetence or restricted by law [15, art. 93]. Generally, people who do not have legal capacity, such as minors (infants), people with significant mental impairments, and excessively intoxicated, are not bound by the contracts and they are excused from performance of the obligations arising from their contract. They can also disaffirm the contract in certain circumstances [18, p. 226].

In smart contracts, the capacity of the parties is not assessed during contract formation. Therefore, minors may have encryption keys to conclude a smart contract or owing bitcoins for example. As a result, if a minor or an excessively drunk person digitally signs a smart contract, there is no chance for the other party to evaluate the personal status or the circumstance from his side. The absence of such a test causes more problematic issues as the parties of smart contracts, from technical point of view, are represented by cryptographic secret keys which are run by computers [17, p. 371]. According to Iraqi law, the conducts of an irrational minor are void and null even if they are permitted by his/her guardian [15, art. 96]. Irrational minor is someone who has not attained the age of seven full years [15, art. 97(2)].

Moreover, some codes may not give information about the identity of the code holder. Even if they do, the holder and the codes cannot be considered as the same. Therefore, it is argued that smart contracts are not agreements between people because of the weak connection between the parties and their agreement, as the execution and enforcement of the contract is entirely left to machines [17].

\subsection{Performance:}

Performance is considered to be an essential part of any contract, without which the contract will not be formed by the parties in the first place. [5, p. 12]. Iraqi law precisely states that the contracting parties are obliged to perform their obligations as agreed upon in the contract [15, art. 145]. In traditional contracts, under the provisions of contract law and according to reasonable person's effort, the performance of some contracts is considered perfect even if it is not exactly the same outcome as expressed in the contract and as the parties expect. This is because the parties are not only bound by the provisions of the contract but also by the provisions imposed by law, custom and equity [15, art. 150(2)].

In smart contracts, however, the performance of each party's obligations is perfect only if they are performed exactly as agreed upon in the contract because computer programs cannot recognise any other outcome apart from the one which is contemplated and specified by the parties [5, p. 7]. Therefore, if the obligations are not performed fully and exactly as stated in the smart contract, the code automatically enforces the available penalties with no consideration for any justification [22, p. 8]. In addition, there is no place for the principle of good faith in smart contracts as it is required by the Iraqi law in performing the obligations of a contract [15, art. 150(1)].

\subsection{Modification:}

Another challenge for smart contracts is amendment. Once a contract is lawfully concluded, it is legally binding and neither party can revoke or amend it except when it is permitted pursuant to a provision in law or by mutual consent of the parties [15, art. 146(1)]. Under the provisions of contract theory, an amendment of a contract is itself a contract. Therefore, it shall follow the same rules and provisions regarding the formation of the original contract [18, p. 186].

Legal provisions permit one or both parties of an agreement for altering the provisions of their signed contract, or even excusing from the performance of their duties without any remedy for the aggrieved party in certain situations. For example, if the performance is impossible or impractical [23, p. 327] [24]. Courts are also allowed to amend a contract to lessen an obligation in accordance with the principle of equity when, due to extraordinary events, the obligation is rendered so onerous [15, art. 146(2)]. It is argued that smart contracts ensure a higher level of certainty because once a smart contract is coded and put on the blockchain, it is fixed to run until it is fully performed [5, p. 9]. However, this may lead to serious legal difficulties since these contracts are operated by computer programs and once they are concluded, it is difficult to change as the blockchain automatically executes the programmed preconditions [13, p. 7]. It is further argued that modifying the provisions of a smart contract on blockchain is even more complicated than changing standard software code, which is not run on blockchain [22, p. 8]. For example, if after concluding a smart contract, the relevant law to an obligation is amended, such as the period to perform the duty, the terms of the contract shall be modified accordingly.

Some solutions have been proposed to incorporate the changes in smart contracts. Some of these solutions are linked to the State authorities to publicise the database and application of the 
relevant legal provisions, in order to enable the smart contracts to be updated accordingly. Other solutions are in the discretion of the parties of the agreement or their agents to update the terms. In this method, the parties may leave certain terms in their contract changeable and others fixed. Consequently, the parties can amend these terms after concluding the agreement if needed. However, this solution has shortcomings as one of the parties may modify these terms unilaterally, which is one of the problematic issues that smart contracts try to resolve [23, p. 327] [20, p. 15].

\subsection{Breach and Remedies:}

As mentioned above, when a contract is lawfully concluded, it shall be performed in accordance with its terms and conditions and in good faith. In bilateral contracts, the promises of the parties to perform the contract is reciprocal i.e. both parties have a duty to fulfil their obligations as stated in the contract [18, p. 7]. However, the parties to an agreement may want to disobey the terms and conditions agreed upon, after concluding their agreement, for several reasons. This option is not available for the parties of the smart contracts, i.e. the parties cannot breach any term of the contract, as they have no control over the automatic run of the code.

Regarding the remedies, they are entitlements arising out of the breach of contractual obligations. When one of the parties breaches an obligation, the non-defaulting party is entitled to enforce specific rights and to impose burdens on the defaulting party. Such remedies include termination of the contract, an award for damages and specific performance [18, p. 11].

In Iraq, specific performance is the default remedy for breach of contractual obligations. When specific performance is not appropriate, compensatory damages are allowed to claim. Additionally, the law permits liquidated damages in specific situations [15, arts. 168-176]. Enforcing such rights is a complex and time-consuming process which sometimes makes the parties to leave the process in order not to spend their money and effort on an uncertain outcome [5, pp. 13-14].

Smart contracts can be used as an effective mechanism to avoid such potential breaches or at least minimising them. The electronic form of these contracts leads to lessening vagueness regarding the terms of the contract compared to traditional contracts. Additionally, the self-executing feature of smart contracts automates the performance of the obligations and the parties have no access to stop the performance or breach any of any term of the contract. Moreover, whenever a breach occurs, sufficient mechanisms can be programmed into the smart contract to provide remedies for the non-defaulting party such as inserting an online dispute resolution clause into the smart contract. Therefore, it is argued that this feature brings a significant relief for the contractual parties on the one hand and for judicial and enforcement system on the other hand [25].

\section{Conclusion and Recommendations}

As discussed in this research, smart contracts, as a new form of contracts which are concluded through the internet, are irreversible, automated and self-enforced agreements. The features of smart contracts can be seen as advantages to this new form of contracts especially regarding their electronic nature which leads to decrease time and effort to conclude contracts. Increasing certainty and self-enforceability of the smart contracts leave no room for breach by one or both parties of the contract.

Further, these contracts are conceptually seen as complete and valid contracts. It seems that some questions surrounding the legal status of smart contracts can be answered by the current contract law doctrines in the Iraqi law. However, there are still several difficulties and uncertainties regarding the formation, legal validity and implementation of such contracts, from both legal and technological perspectives. This is because the concept of smart contracts is relatively new compared to traditional contracts and their legal provisions.

Additionally, IT infrastructure and network development seem to be another obstacle to implement smart contracts in Iraq.

Therefore, it is suggested that the Iraqi law (specific rules related to contracts) must be reformed in order to provide solutions for such advancement in the field and to make the most of this development in the area. This can be done by amending the current rules or adopting new rules specifically to smart contracts and blockchain technology, to allow forming the contracts in other ways than just the traditional model. In addition, more researches and studies in this regard are recommended to cover all the aspects of smart contracts, in order to pave the path to the Iraqi legislator to update or adopt new rules to integrate smart contracts into the current legal system.

\section{References}

\section{Statutes and Conventions}

Electronic Signature \& Electronic Transactions Law, No. 78, 2012.

Iraqi Civil Code, No. 40, 1951.

United Nations Commission on International Trade Law, UN Convention on the Use of Electronic Communications in International Contracts, 2005.

Books

Fery, M. A., (2000). Introduction to the Law of Contract (3rd ed.). Tomson Delmar Learning.

Kolvart, M., Poola, M. \& Rull, A., (2016). Smart Contracts. In The Future of Law and eTechnologies. Springer International Publishing Switzerland.

O'Sullivan, J. \& Hilliard, J., (2014). The Law of Contract (5th ed.). Oxford University Press.

Stone, R., (2009). The Modern Law of Contract (8th ed.). RoutledgeCavendish.

\section{Journal Articles}

Ayub, Z. A., Mohamed, K. \& Aziz, Z. I. (2017). The Legal Challenges of International Electronic Contracts in Iraq. International Journal of Social Science Research, 5 (2), 57-72.

Kamantauskas, P. (2015). Formation of Click-Wrap and Browse-wrap Contracts. Teisès apžvalga Law Review, 1 (12), 51-88.

O'Shields, R. (2017). Smart Contracts: Legal Agreements for the Blockchain. 
North Carolina Banking Institute, 21 (1), 177-194.

Raskin, M. (2017). The Law and Legality of Smart Contracts. Georgetown Law Technology Review, 1 (2), 305-341.

Savelyev, A. (2017). Contract law 2.0: 'Smart' contracts as the beginning of the end of classic contract law. Information \& Communications Technology Law, 26 (2), 116-134.

Werbach, K. \& Cornell N. (2017). Contracts Ex Machina. Duke Law Journal, $67,313-382$.

\section{Miscellaneous}

Catchlove, P. (2017). Smart Contracts: A New Era of Contract Use. [Online]. https://ssrn.com/abstract=3090226

Clack, C. D., Bakshi, V. A. \& Braine, L. (2016). Smart Contract Templates: Foundations. Design Landscape and Research Directions. CoRR abs/1608.00771 available at <http://arxiv.org/pdf/1608.00771v2.pdf> accessed 10 February 2018,

E. T. T. Tai, "Force Majeure and Excuses in Smart Contracts," in Impact of Technology on International Contract Law: Smart Contracts and Blockchain Technologies, Lyon, 2018.

Hansen, J. D. \& Reyes, C. L. (2017). Legal Aspects of Smart Contract Applications. [Online]. https://www.perkinscoie.com/en/newsinsights/legal-aspects-of-smart-contract-applications.html.

Hourani, S. (2017). Cross-border Smart Contracts: Boosting International Digital Trade through Trust and Adequate Remedies. In UNCITRAL Congress on 'Modernizing International Trade Law to Support Innovation and Sustainable Development. [Online] https://bit.ly/2L71KdK.

Hulicki, M. (2017). The Legal Framework and Challenges of Smart Contract Applications. In International Conference on Artificial Intelligence and Law. [Online]. https://bit.ly/2uJqbQZ

Jaccard, G. (2017). Smart Contracts and the Role of Law. Jusletter IT 23. [Online] https://jusletter-it.weblaw.ch/en/issues/2017/23-November2017.html

Lauslahti, K., Mattila, J. \& Seppälä, T. (2017). Smart Contracts - How will Blockchain Technology Affect Contractual Practices?. ETLA Reports 68.

Levi, S. D. \& Lipton, A. B. (2018). An Introduction to Smart Contracts and Their Potential and Inherent Limitations. [Online] https://corpgov.law.harvard.edu/ or https://bit.ly/2No4Vru

Szabo, N. (1996). Smart Contracts: Building Blocks for Digital Markets. Extropy \#16. [Online]. https://bit.ly/2htGy10

Szczerbowski, J. J. (2017). Place of Smart Contracts in Civil Law. A Few Comments on Form and Interpretation. In the 12th Annual International Scientific Conference NEW TRENDS 2017, pp. 333-338. [Online]. https://ssrn.com/abstract=3095933

Verstraete, M. (2018). The Stakes of Smart Contracts. Arizona Legal Studies Discussion Paper No. 18-20, 1-49. 